\title{
Integration of InSAR and GPR Techniques for Monitoring Transition Areas in Railway
}

\section{Bridges}

\author{
Fabrizio D'Amico ${ }^{1}$, Valerio Gagliardi ${ }^{1}$, Luca Bianchini Ciampoli ${ }^{1 *}$, Fabio Tosti ${ }^{2}$
}

${ }^{1}$ Department of Engineering, Roma Tre University, Via Vito Volterra 62, 00146, Rome, Italy. (email: fabrizio.damico@uniroma3.it; valerio.gagliardi@uniroma3.it; luca.bianchiniciampoli@uniroma3.it)

${ }^{2}$ School of Computing and Engineering, University of West London (UWL), St Mary's Road, Ealing, London, W5 5RF, UK. (email: Fabio.Tosti@uwl.ac.uk)

Correspondence: luca.bianchiniciampoli@uniroma3.it

\section{Highlights}

- Differential settlements at the bridge-infrastructure transition zone are demanding in terms of maintenance required.

- An integrated approach combining ground penetrating radar and satellite interferometry is proposed to provide a more comprehensive assessment of differential settlements.

- A case study on a real railway bridge is presented.

\section{Abstract}

This paper reports the integration of the Ground Penetrating Radar (GPR) and the Interferometric Synthetic Aperture Radar (InSAR) techniques for the monitoring of the rail-abutment transition area in railway bridges. To this purpose, an experimental campaign was conducted on a rail truss bridge located in Puglia, Southern Italy. On one hand, GPR was used to obtain structural details of the subsurface (thickness of the ballasted layer, position of the sleepers, presence of clay/humidity spots) and to identify potential construction-related issues. Parallel to this, InSAR analyses were mainly addressed to monitor subsidence at the rail-abutment transition area. Outcomes of this investigation outlined presence of subsidence at both the areas of transition and have proven the proposed integrated approach as viable to achieve a more comprehensive assessment of the structural integrity of railway bridges.

Keywords - Ground Penetrating Radar, GPR, Interferometric Synthetic Aperture Radar, InSAR, Permanent Scatterers, PS-InSAR, Data Fusion, Railway Monitoring, Transport Infrastructure Maintenance 


\section{Introduction}

\subsection{Background}

Development of new assessment strategies for damage characterisation in railway transport infrastructures is crucial to meet satisfactory standards in terms of safety, functionality and resilience over time.

Typically, the evaluation of the asset resilience against major natural events (i.e. landslides or earthquakes) or anthropic-related events is conducted separately from the decay monitoring of safety standards and structural aspects of the infrastructure. Furthermore, the severe exposition and vulnerability of railway networks to major adverse events and a few structural collapses affecting transport infrastructures in recent times, have emphasised on the importance of identifying novel and effective health monitoring strategies. It is also worth mentioning that scarcity of funding for maintenance and lack of advanced technologies with a network-level applicability constrain to provide an effective assessment of the infrastructure.

Railway systems consist of interconnected infrastructures including bridges, viaducts and tunnels, where single elements not working at full capacity can affect the functionality of the entire system. Within this context, it is worth noting that a growing number of bridges all over the world have been classified as structurally deficient in the past two decades [1]. Estimated financial costs for maintenance are very high along with social costs that will be affected by compromising safety standards. To this effect, it is important to remind that maintenance of bridges and their structural components, such as stacks and shoulders, and monitoring of their static and dynamic response is not an easy task. This is due to the amount of variables involved, such as the provision of a proper design, infrastructure usage and working conditions, and degradation of structural materials. 


\subsection{Track degradation process at bridge-infrastructure transition areas}

It is known that a free rail track within its lifetime is subject to settlements caused by the action of soil creeping, traffic conditions and the interaction between soil and water [2]. On the contrary, a more comprehensive and constrained design of foundations in structures such as bridges will make these settlements usually negligible, especially in case of deep foundations. This occurrence results in a differential settlement at the transition area between the bridge structure and the railway infrastructure.

Differential settlements require several maintenance actions at the bridge-infrastructure transition zone. As an example, maintenance activities in the Netherlands railway network are three times more frequent in these areas compared to other sections of these infrastructures [3]. This requires more detailed investigations to identify the source of decay. To this effect, factors that are either not active or negligible in the degradation process of free tracks may escalate and cause differential settlements at the transition areas. Uneven distributions of stiffness and damping between the bridge and the approach, geotechnical-related issues, and soil-water interaction are key factors that may trigger a process of track degradation in these areas $[2,4,5]$. This sudden stiffness variation generates an extra dynamic energy within the transition area [6]. In this context, the movement direction of trains critically exacerbates the effects of this occurrence. When a train passes from a higher (i.e., the bridge structure) to a lower (i.e., the approach area) stiffness section, a higher dynamic load is applied to the transition area, thereby causing localised settlements $[2,6]$. The expected dynamic load is here twice the amount of the quasi-static load [7] and can cause migration of ballast aggregates and tie movements [8].

Special focus on failure modes at the subgrade level is essential to identify potential geotechnical issues in transition areas. It is known that progressive shear failure and excessive plastic settlements are primary failure modes in subgrades [9]. In addition to this, Burrow et al. [10] state that rail track 
foundation design frameworks require consideration of these two failure modes, especially at the upper layers, where dynamic load is more significant.

Metric suction of unsaturated soil is a governing factor to control shear strength and soil deformation [11]. On the contrary, soil metric suction is strongly related to soil moisture, which is highly sensitive to climate changes [12]. Particle size distribution, clay percentage, soil type, soil fabric orientation, and drainage boundary conditions further control metric suction as well as pore water pressure increments caused by dynamic loads [12-14]. In fact, pore-water pressure decreases soil suction as well as the effective shear strength.

Within this context, mitigation techniques aim to improve the performance of the main structural components in a transition area i.e., the bridge, the superstructure and the substructure of the approach. These can be sorted into three groups based on their functions, including: $i$ ) a reduction of the vertical stiffness or an increase of the damping on the bridge, ii) smoothening of settlements at the transition area by increasing the bending stiffness of the rail-tie structure at the softer section of the transition, iii) smoothening of the track modulus distribution along the bridge transition area $[2,4,15,16]$.

\subsection{Statement of the problem}

Non-destructive testing (NDT) methods have contributed significantly to improve the productivity and the effectiveness of inspection activities over large railway assets [17]. Nevertheless, a standalone application of these techniques can only provide partial condition-based assessment of the infrastructure [18]. Every technique has both advantages and limitations, which are mainly related to aspects such as the spatial resolution, operational productivity and working principles. Accordingly, selecting single NDT equipment can lead to a comprehensive assessment of a particular type of distress and compromising over others [19]. 
Within this context, use of multi-scale information collected with different monitoring techniques (e.g., ground-based NDT methods and satellite remote sensing) under a "data fusion" approach, can represent a practical and novel methodology to overcome gaps and limitations from use of single techniques, leading to an enhanced and more comprehensive assessment of the infrastructure [19, 20].

To this purpose, a proper selection of available NDT and remote sensing methods for railway monitoring purposes is necessary to achieve full knowledge of the asset conditions at the network level, with special reference to the system resilience towards exogenous and endogenous events.

In this paper, a novel approach based on the integration of Ground Penetrating Radar (GPR) and Synthetic Aperture Radar Interferometry (InSAR) inspection techniques is presented, with a special focus on the transition areas between the rail and the bridge abutment in railways. The paper is outlined as follows. In chapter 1 , a discussion on the degradation of rail tracks at the bridgeinfrastructure transitions areas was given. Chapter 2 discusses aims and objectives of the study. The assessment methods used in this study are described in chapter 3, along with the proposed integrated approach. Chapter 4 presents a case study about the investigation of a real-life railway track with the proposed approach. Results and discussion are presented in chapter 5 and conclusions and future prospects are outlined in chapter 6.

\section{Aim and Objectives}

The main aim of this paper is to investigate the potential of the integration between satellite remote sensing and ground-based non-destructive methods for the effective monitoring of bridgeinfrastructure transition areas in heavily-solicited infrastructures.

To achieve this aim, the following objectives are identified: 
- to prove the viability of using InSAR and GPR as stand-alone monitoring techniques for the identification of surface and subsurface decay, respectively, at bridge-infrastructure transition areas in railway bridges;

- to explore the feasibility of integrating information from multi-source and multi-scale datasets and verify benefits of this approach for identification of causes of decay.

\section{Assessment Methods}

A review given by [17] reports the application of various NDT techniques and highlights different performance levels achievable in terms of resolution and productivity (Tab. 1).

Tab. 1 - Non-destructive and remote sensing methods in railway monitoring

\begin{tabular}{lcc} 
Inspection technique & Information & Reference \\
\hline Laser-based & Track alignment/Deformation of rails & {$[21]$} \\
$\begin{array}{l}\text { Inertial methods } \\
\text { Image Analysis }\end{array}$ & Deformation of rails & {$[23]$} \\
Acoustic methods & Defects in rails and sleepers & [24] \\
Ground Penetrating Radar & Subsurface track-bed issues & [25] \\
Deflectometry & Stiffness of the track-bed & {$[26]$} \\
Satellite interferometry & Subsidence phenomena & {$[27]$} \\
Ground-based interferometry & Stiffness of the track-bed & {$[28]$}
\end{tabular}

In line with the aforementioned objectives of the research, the working principles and the main characteristics of two inspection techniques, i.e., GPR and InSAR, are presented in this section along with the rationale behind their integration.

\subsection{Ground Penetrating Radar}


GPR is nowadays recognised as one of the most reliable and efficient geophysical inspection tools for the investigation of the geometric and physical features of the subsurface $[29,30]$. This technique works by generating and radiating short electromagnetic pulses within a medium. When the transmitted wave hits a target with different electromagnetic properties, part of the energy reflects back and is recorded by a receiving antenna, and rest of the energy propagates in depth until it gets dissipated. The reflected wave contains information about the electromagnetic properties of the target, whereby indirect information about geometric and physical properties can be extrapolated through the application of dedicated data processing algorithms and filters.

In general terms, GPR has proven effectiveness for the monitoring of transport infrastructures, due to a good number of advantages compared to traditional inspection techniques. A wide applicability of GPR has been demonstrated in both road investigations [31-33] and railway investigations [3438] due to the rapidity of data collection and the availability of a wide range of frequencies, which can provide information with different resolutions and penetration depths [39].

Several researches has been reported on successful GPR applications in bridge inspections. These were mainly aimed at assessing the health conditions of concrete and reinforcements in bridge decks using high-frequency antenna systems [40-44]. Within that context, both ground-coupled antennas (i.e. working at contact with the ground) and air-coupled antennas (i.e. working with an offset between the antenna and the ground) were employed. However, despite significant research developments achieved in the last few decades, some drawbacks in the stand-alone use of GPR still exist, which can limit areas of applicability. In fact, GPR is reported to provide a quite advanced assessment of the physical conditions of the inspected elements, whereas subsidence and failures involving the entire structure might be neglected.

\subsection{Persistent scatterers InSAR}


In the last decades, several techniques have been developed for earth surface monitoring purposes in order to exploit space-borne data from both Synthetic Aperture Radar (SAR) and Multispectral sensors [45-49]. More specifically on civil engineering applications, satellite remote sensing has proven to be effective for transport infrastructure condition assessment. The main benefit of this method is the provision of information on the overall structural stability of the asset and the surrounding environment by analysing a multiple set of SAR image outputs collected at different time periods.

However, the implementation of the InSAR technique is generally affected by several different factors, i.e. the signal interference caused by adverse atmospheric conditions, the temporal decorrelation due to the variation of the scattering properties over time and the geometric decorrelation due to the variation of the acquisition geometries arising from the distance between different satellite orbits [50, 51]. These factors affect the accuracy of the analysis. To tackle the problem, various processing techniques have been proposed over time and, among these, the Permanent Scatterers InSAR (PS-InSAR) method $[45,52]$ is one of the most acknowledged. This technique is based on a statistical analysis of the signals back-scattered from a network of phasecoherent targets, named as Permanent Scatterers (PS). These are defined as points on the ground returning stable signals to the satellite sensor. To this extent, the constant scattering properties of a PS over time and the reflection dominance within a pixel cell are effective in reducing the temporal and geometric decorrelations. In addition, adverse effects given by the atmospheric conditions can be estimated and removed using the series of images collected at different time frames.

The development of the PS-InSAR technique has paved the way to a number of applications for the monitoring of linear transport infrastructures [53-57]. Availability of historical series of displacements allows for a more reliable prediction of the trend of deformations for structure and infrastructure systems as well as the surrounding investigated environment. On the contrary, this 
task is nowadays only partially possible with the available on-field technologies, such as inclinometers, strain gauges and total stations. A main drawback for these pieces of equipment is that they can only provide a documented series of deformations at the time and location point of the instrumentation. Moreover, installation is very demanding in terms of time and human resources required. On the other hand, the InSAR technique allows to monitor the transport infrastructure assets at the network level and does not require on-site installation of any additional equipment.

Although the method has proven high capabilities in track displacement diagnostics and wide effectiveness to assist scheduling of maintenance activities, PS-InSAR has not been yet fully implemented as a routine inspection technique for railway infrastructure management purposes. It is the Authors' view that this can be most likely due to the type of information provided, which finds its main scope in the assessment of the geotechnical and structural behaviours of bridges on a longterm base. On the opposite, use of the PS-InSAR technique as a stand-alone diagnostic method cannot provide point information on the conditions of construction materials and performance of a structure/infrastructure at specific sections subject to the application of external loads.

\subsection{The data integration concept}

Despite GPR and PS-InSAR methodologies can both collect a considerable amount of data on the transport asset conditions, outcomes are incomplete if considered singularly, as they are both constrained in evaluating either surface or subsurface conditions.

In this research, an integration between GPR and PS-InSAR techniques is proposed to combine flexibility, high-resolution and capability to identify sources of shallow decay of GPR, with the provision of temporal evolution trends of decay at the network level of PS-InSAR [18]. This integrated monitoring approach is expected to increase the reliability of the assessment and 
contribute to mantain the resistance of the infrastructure to both major external events and internal decay, leading to an extended concept of infrastructure resilience [19, 58-61].

\section{Case Study}

An experimental activity was conducted to test the suitability of the integration between the above two techniques for the monitoring of bridge-infrastructure transition areas. The area in the vicinity of a railway truss bridge overpassing a motorway was investigated by the PS-InSAR technique, whereas high-frequency GPR systems were used for surveying the track-bed. This research stems from a wider investigation developed over the entire railway network in the municipality of San Severo, Italy [18].

\subsection{The test site}

A 12-km long stretch of a newly built ballasted railway track was considered for the purpose of this study (Fig. 1a). This track section includes a truss bridge overpassing the "A14" Italian motorway (Fig. 1b).
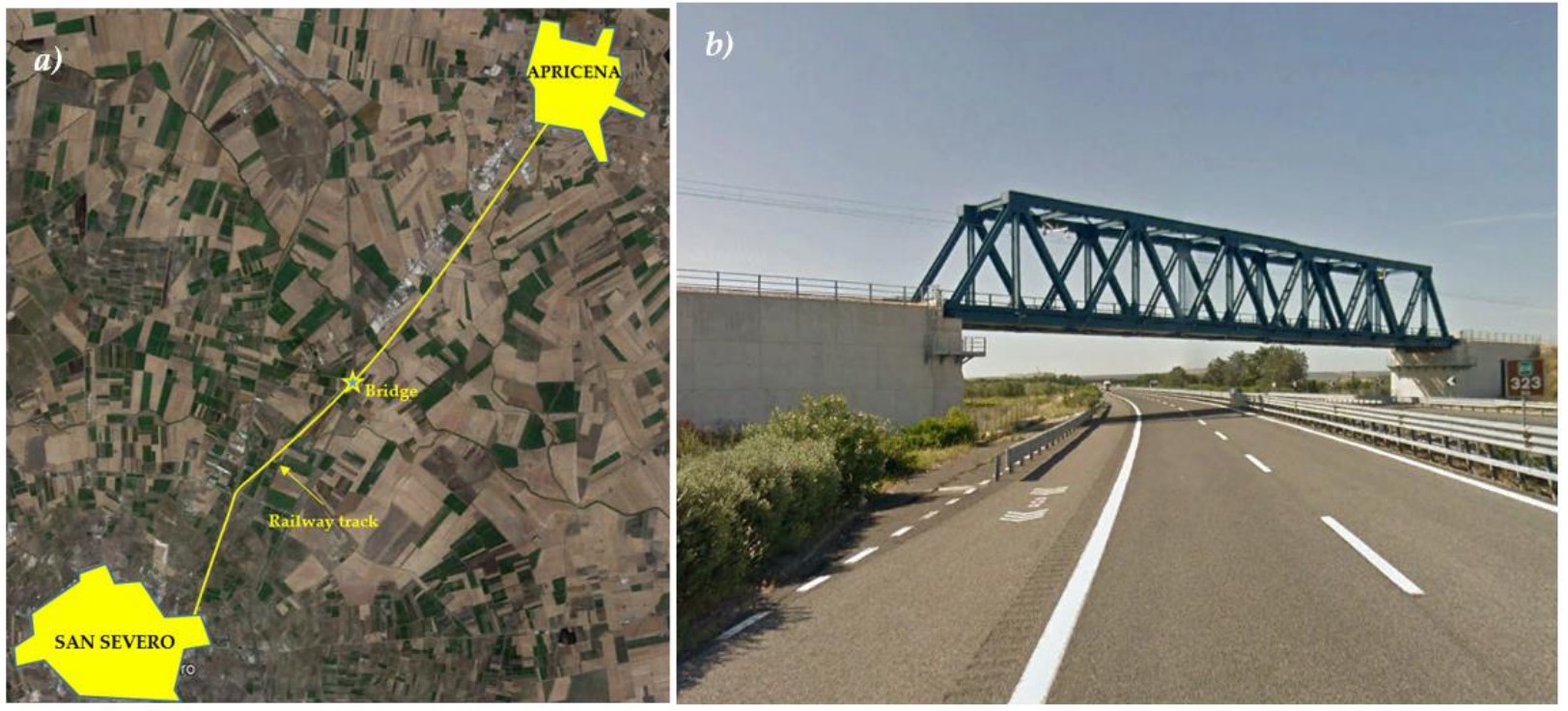

Fig. 1 - Geographical framework of the test site (a) and the truss bridge overpassing the "A14" Italian motorway (b) 
The line was inhibited to daily transport service during the tests, thereby allowing for safe and secure surveys.

The ballasted railway track under investigation (Fig. 2) was put into service in 2013. It is composed of an average $70 \mathrm{~cm}$-thick limestone ballast layer on which mono-block pre-stressed concrete sleepers are laid. Dry conditions were assumed for the track-bed at the time of the surveys, according to the long-standing dry climate and an average monthly air temperature of $16^{\circ} \mathrm{C}$.

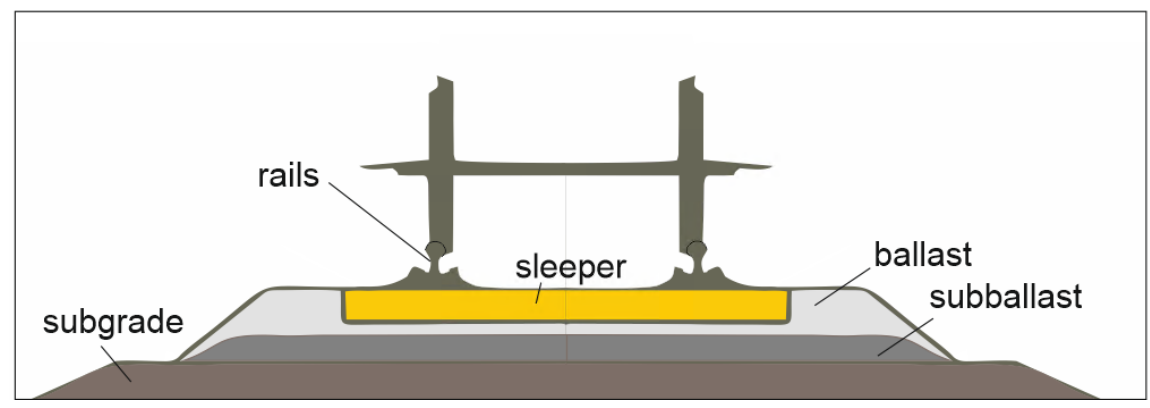

Fig. 2 - Cross-section of the investigated rail track-bed

\subsection{GPR test equipment and InSAR imagery}

GPR surveys were performed using a pulsed system equipped with two horn antennas of $1000 \mathrm{MHz}$ and $2000 \mathrm{MHz}$ central frequencies, manufactured by IDS Georadar (Part of Hexagon) [62]. Antennas were mounted onto a real train convoy and suspended in the air at a height of $45 \mathrm{~cm}$ from the ground [63]. Following manufacturer's recommendations, data acquisitions were performed with time windows of $25 \mathrm{~ns}$ and $15 \mathrm{~ns}$ for the $1000 \mathrm{MHz}$ and the $2000 \mathrm{MHz}$ antennas, respectively. Number of samples per trace were 512 for both the configurations. A horizontal trace step of $5 \mathrm{~cm}$ was set for data collection purposes, and controlled by means of a Doppler-based odometer. Auxiliary systems (i.e., a GPS system and high resolution cameras) were employed for testing purposes. Data were 
collected at an average survey speed of $40 \mathrm{~km} / \mathrm{h}$. The connection support for the antennas and all the testing devices were mounted on an ETR 330 convoy (Fig. 3), normally operating on the investigated railway line.

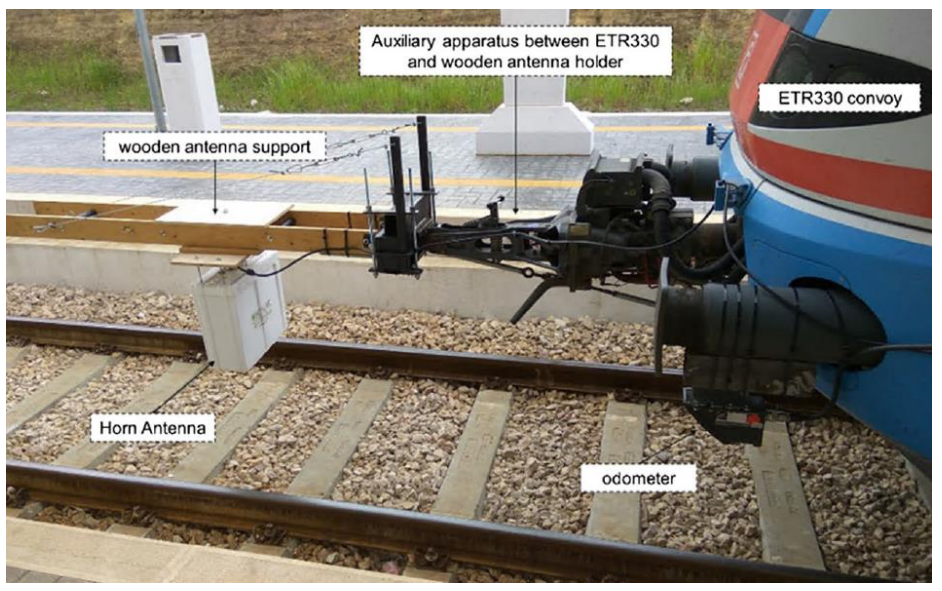

Fig. 3 - The GPR test equipment [18]

The GPR dataset has been processed according to the following sequential steps [33]:

- time-zero correction;

- de-wow;

- background removal;

- band-pass filtering (bandwidth equal to 1.5 the nominal frequency);

In regard to the application of the SAR imagery technique, data were collected in ascending and descending geometries using medium and high spatial resolutions. In more detail, a stack of 44 images from Sentinel 1A ("produced from ESA European Space Agency, remote sensing data"), operating in $C$ band, were processed. In addition to this, 56 stripmap images collected in ascending and descending geometries from the COSMO-SkyMed mission (COSMO-SkyMed Product - CASI: 
Italian Space Agency, 2016-2017, All Rights Reserved), operating in X-band, have been processed. Main features of SAR dataset are reported in Tab. 2.

Tab. 2 - Main features of the SAR imagery dataset

\begin{tabular}{lcc} 
& Sentinel 1A & COSMO-SkyMed \\
\hline Number of Images & 44 & 56 \\
Reference Period & $04 / 2017-01 / 2018$ & $03 / 2016-01 / 2018$ \\
Frequency & $5.4 \mathrm{GHz}$ & $9.6 \mathrm{GHz}$ \\
Ground-Range Resolution & $5 \mathrm{~m}$ & $3 \mathrm{~m}$ \\
Azimuth Resolution & $20 \mathrm{~m}$ & $3 \mathrm{~m}$ \\
\hline
\end{tabular}

These products have been acquired and processed using the PS technique of SARscape Interferometric Stacking Module, integrated in Envi software [64, 65], within the framework of the project "MOBI: Monitoring Bridges and Infrastructures Networks" (proposal ID 52479), approved by the European Space Agency (ESA).

The processing algorithm includes the following steps [64-66]:

- generation of differential interferograms out of the stack of SAR images;

- selection of candidate PS points;

- coherence-based filtering of the dataset;

- phase unwrapping;

- evaluation of spatial, orbital and atmospheric decorrelations;

- calculation of deformation time series.

\section{Results and Discussion}




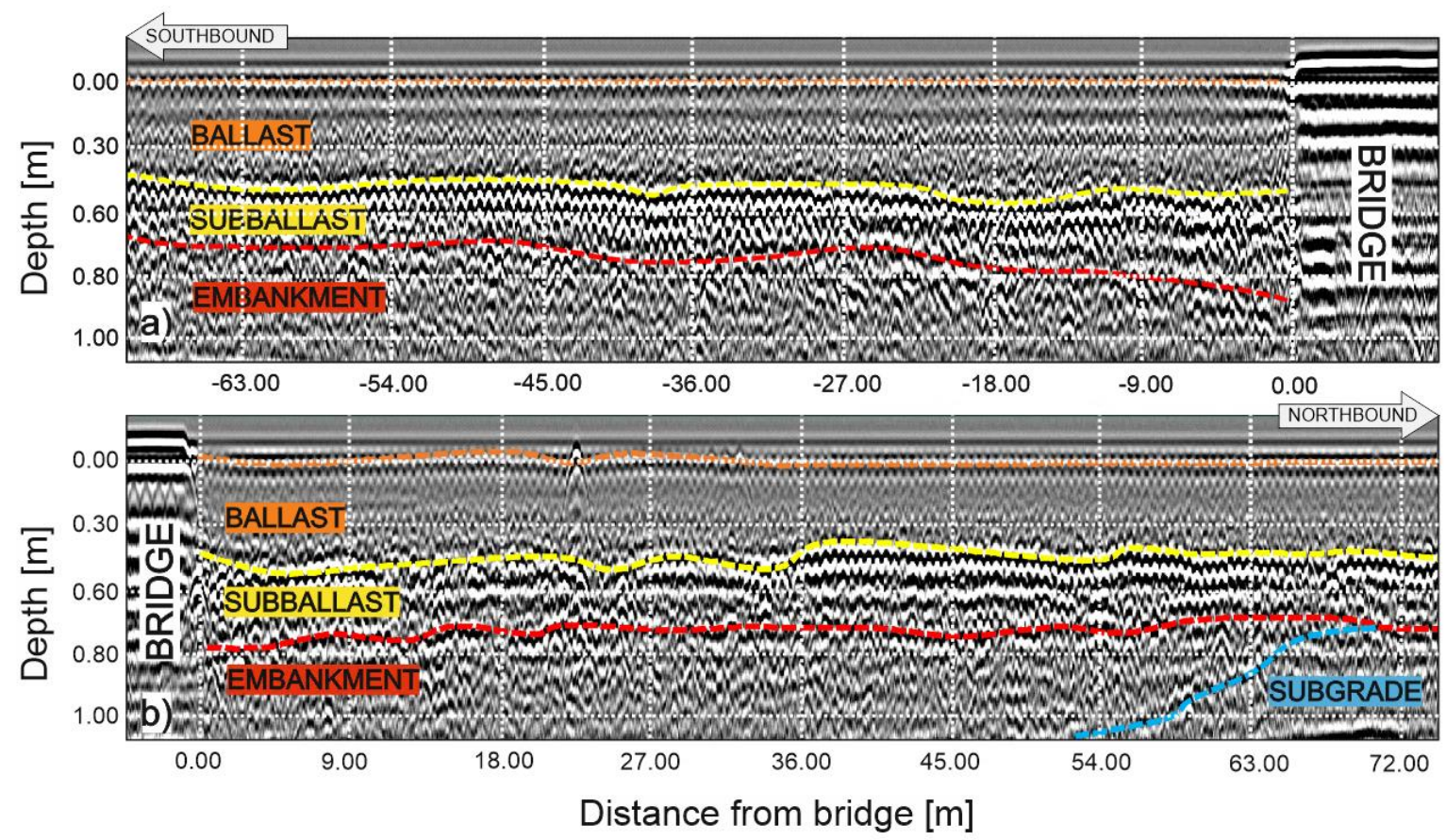

Fig. 4 -Radargrams collected before (top) and after (bottom) the rail truss bridge with the $1000 \mathrm{MHz}$ horn antenna system

It is worth noting that the height of the embankment varies according to the geomorphological features of the area. From the available design charts (Fig. 5), the height of the embankment is different at the two approaches of the bridge. Height is constant in the southbound direction, whereas it decreases rapidly moving away from the bridge in the northbound direction. This is also verified by the GPR scans (Fig. 4b), where the depth of the interface between the embankment and the subgrade is observed to decrease between $50 \mathrm{~m}$ and $70 \mathrm{~m}$ from the bridge. 


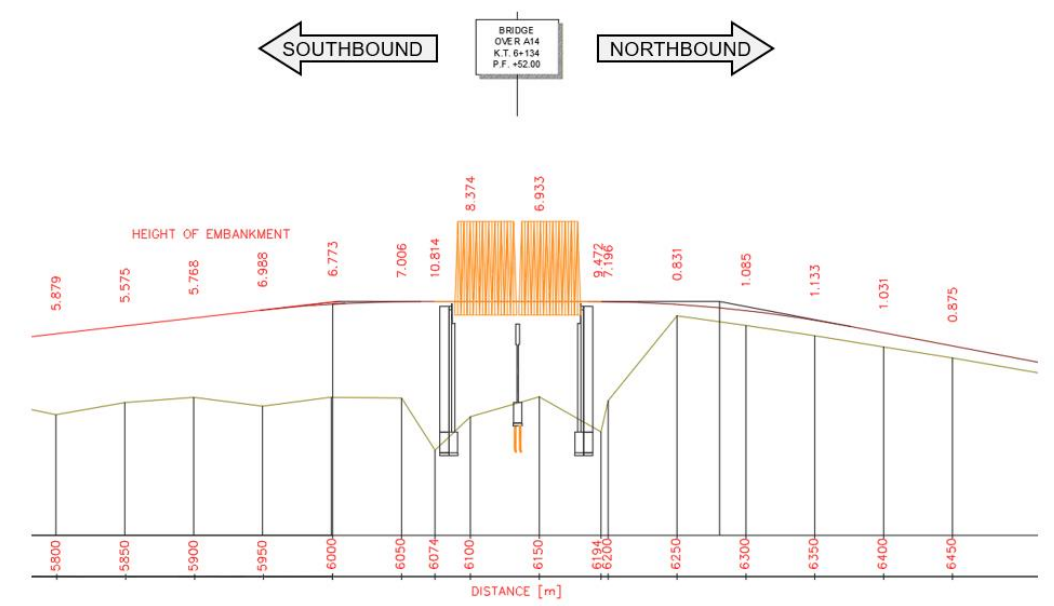

Fig. 5 - Railway vertical alignment showing the height of the embankment in the approaches to the bridge

Analyses of the GPR scans also identified a 10 m-long section at the southbound approach with a

higher reflectivity at the subballast-embankment interface, at approximatively 25-m distance from

the bridge (Fig. 6). This may be related to a higher compaction rate exerted by the cyclic action of dynamic loading on the ballasted layers of the track. To this effect, it is known that the passing convoys may generate stress forces higher than the shear strength between the ballast aggregates, especially at high speeds. This can cause the aggregates to segregate into finer particles and move

from their original arrangement. Fine materials produced in this process tend to deposit at the bottom of the load-bearing layers (i.e., at the interface with the embankment) affecting the reflectivity of the dielectric discontinuity represented by the layer interface [38].

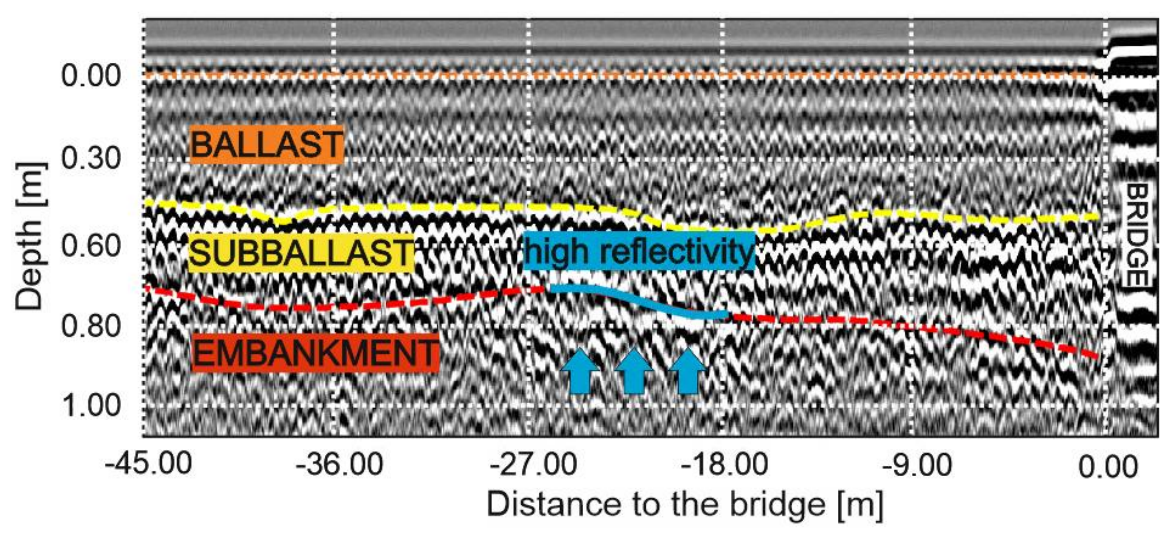


In regard to the results obtained by the application of the PS-InSAR technique, several PSs were identified on the railway-track at the location of the truss bridge and its approaches. Outcomes of this processing carried out on the COSMO Sky-Med dataset are reported in Fig. 7.

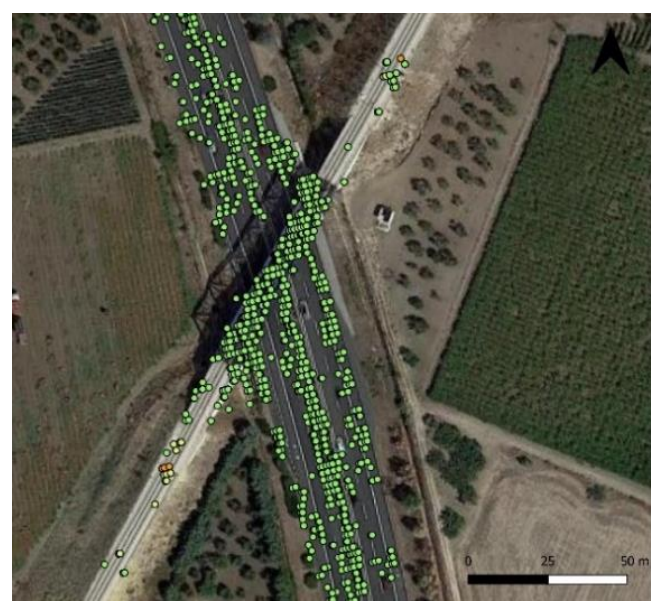

Fig. 7 - PS-outcomes from the InSAR analysis carried out on the truss bridge area

Several down-lifting PSs were detected at both the southbound and the northbound approaches, as shown in Fig. 8a,b. Two distinct trends were observed by way of comparison between the average trend of displacements of the PSs located in the vicinity of the bridge (i.e., less than $20 \mathrm{~m}$ from the bridge, green trend line in Fig. 8c,d) and those observed at a distance between 20 to 50 m (orange trend line in Fig. 8c,d). Grey connectors represent the specific trends of single PSs, whereas green and orange trend lines represent the averaged trends. To this effect, while the former have a quasihorizontal trend over time with some expected seasonal oscillations, the latter highlights an evident trend of subsidence, especially at the southbound approach to the bridge. In more detail, average deformation rates of $12 \mathrm{~mm} /$ year and $4 \mathrm{~mm}$ /year in the Line-of-sight direction were observed for the two sections closer to the bridge in the southbound and the northbound approaches, respectively (orange trend lines in Fig. 8c,d). This observation agrees with the outcomes of the GPR surveys discussed previously (Fig. 6). 

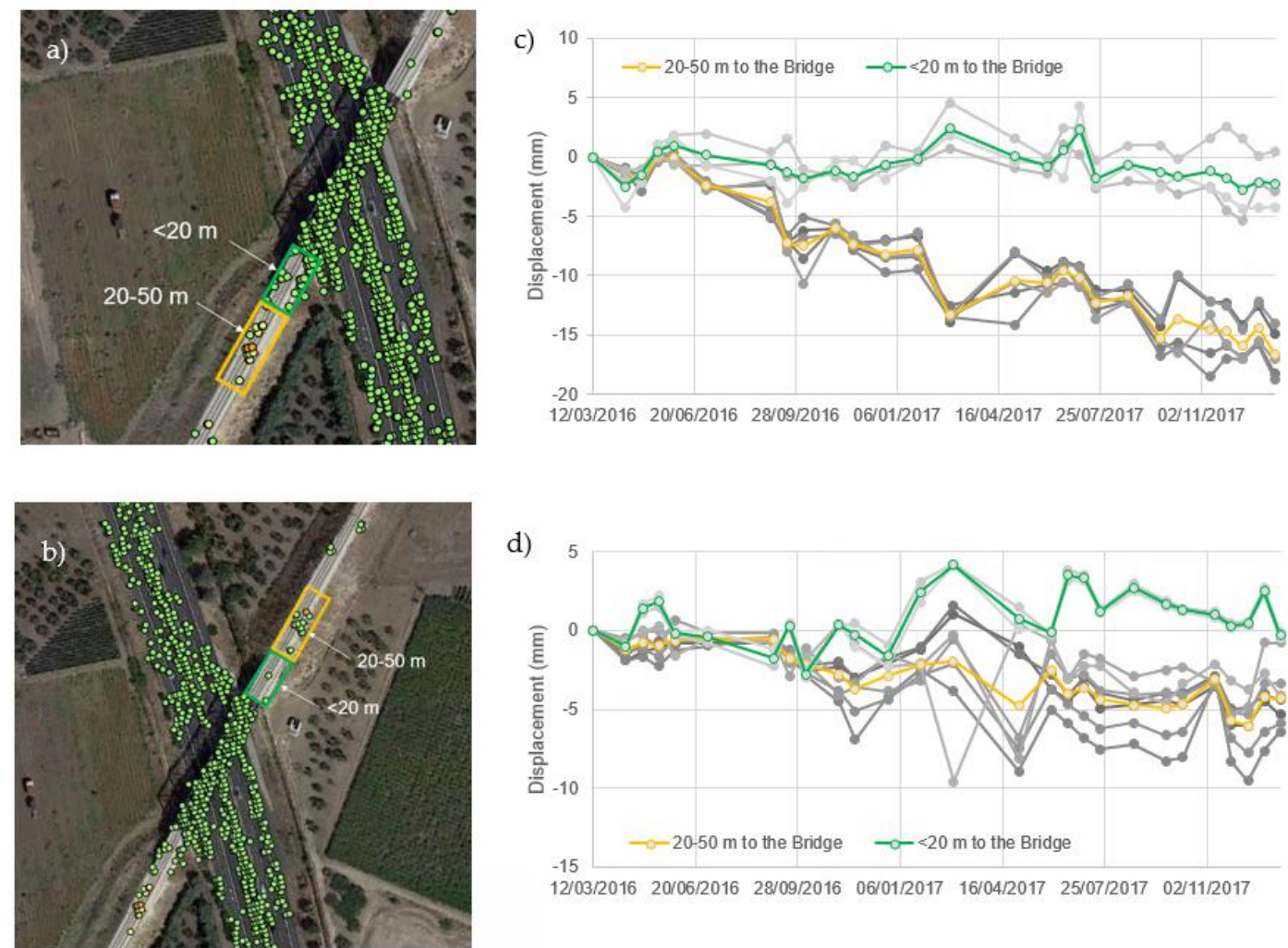

d)

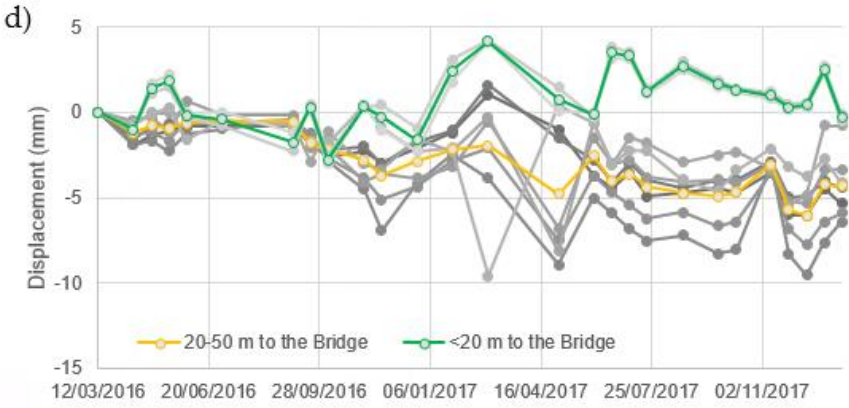

Fig. 8 - PS-InSAR analysis of the a) southbound and b) northbound approaches to the bridge, with relevant deformation trend analysis $(c, d)$

It is worth noting that the two areas subject to subsidence are symmetrically located with respect to the bridge position; more specifically, subsidence is observed at the end section of the abutment wing walls, as it is shown in Fig. 9. This may imply that lateral retention of the wing walls tends to increase the shear strength of the deep layers, thereby inhibiting progression of vertical subsidence in time. To this effect, it was noticed that displacements start to be observed as the effects of this mechanism attenuate (i.e. beyond the end section of the wing walls). 

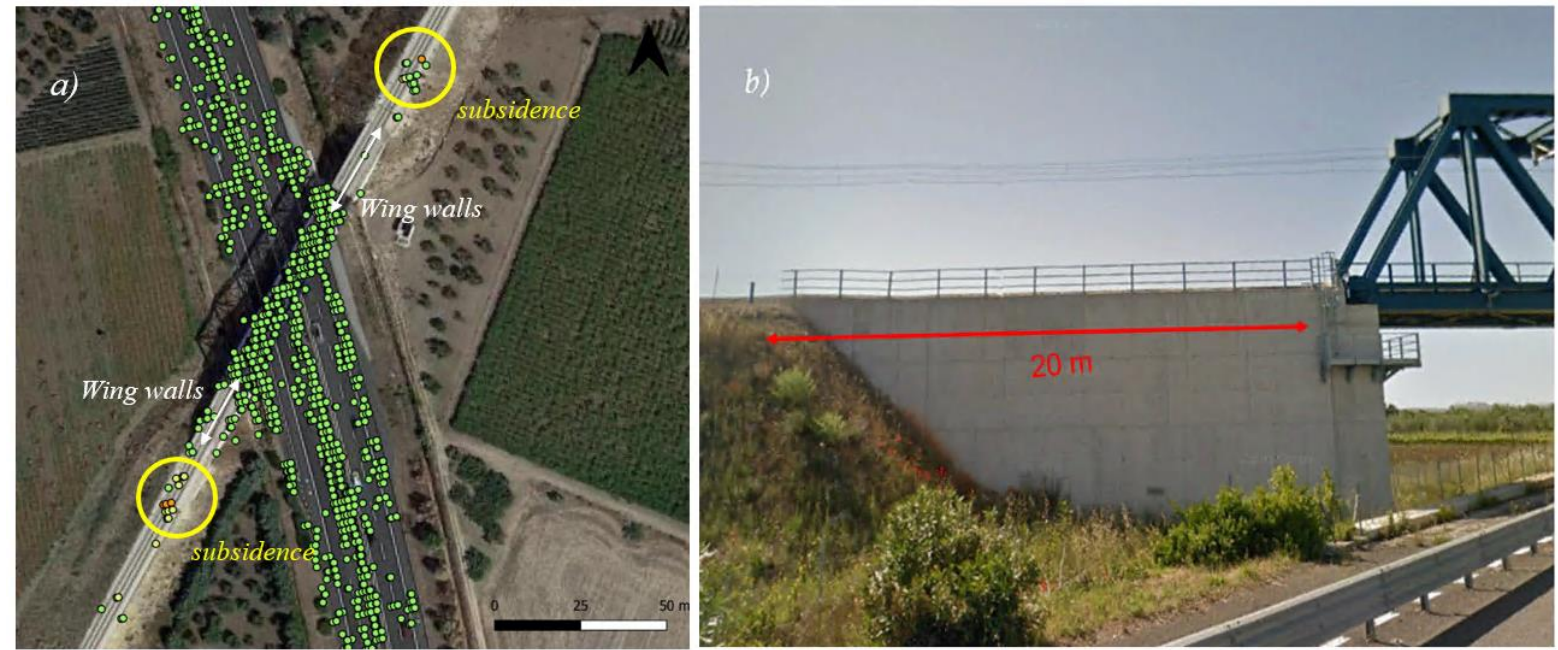

Fig. 9 - (a) Evidence of subsidence at the approaches of the bridge by InSAR analysis, (b) wing walls detail

It is also worth mentioning that the above occurrence is more pronounced at the southbound approach compared to the northbound approach. This is most likely related to the larger height of the embankment (Fig. 5) and, subsequently, to the higher self-weight of the structure. This inherently exposes the track to a higher risk of settlements, when subject to the action of dynamic loads from the passing convoys.

It is important to emphasise that reconstruction of the trackbed features of the superstructure produced by the GPR surveys returned a very regular profile, thereby excluding any potential structural or construction-related cause for the observed settlements. In this sense, the potential of the proposed integrated methodology as a supporting tool for planning effective maintenance interventions is well stressed out.

\section{Conclusions and Future Prospects}

This paper reports the integration of the GPR and the PS-InSAR techniques for the monitoring of the rail-abutment transition area in railway bridges. Results from the experimental campaign carried out on a rail truss bridge highlighted the presence of subsidence spots at the approaches of the bridge. GPR surveys allowed to verify the regularity of the structure at both the approaches, thereby 
allowing to exclude potential construction-related issues. Further to this, a section of the railway at one specific approach (i.e. the southbound approach) with a high-reflectivity area at the deeper layers was identified by GPR. A possible explanation to this occurrence was related to the higher compaction rate of the ballasted layers due to the contribution of a higher dynamic loading exerted by the trains and the larger height of the embankment at that section. Parallel to this, the PS-InSAR analysis has proven this section to be affected by an anomalous subsidence process. To a lesser extent, this was also verified at a symmetrical distance from the bridge centerline section, on the other approach (i.e. the northbound approach). Settlements were mostly located at the end of the wing walls of the abutment, due to potential higher effects of the dynamic loads where the retaining action of the wing walls terminates.

To conclude, the implementation of the two systems in this case study has proven successful and it has paved the way for further investigations in similar scenarios (i.e., bridge-infrastructure transition areas in heavily-solicited infrastructures) to confirm the outcomes of this research. Within this context, InSAR could be applied to preliminary identify areas of concern at the network level, whereas GPR could be used to detect effectively decay sources. The approach could find potential application in the future within the context of providing a more effective prioritisation of interventions in railway maintenance programs.

\section{Acknowledgements}

The license for using the software ENVI SARscape ${ }^{\circledR}$ is granted by the ESA-approved project "MOBI: Monitoring Bridges and Infrastructure Networks" (EOhops proposal ID 52479). The COSMO-SkyMed StripMap HIMAGE images (CSK® Products) are (C of the Italian Space Agency (ASI), delivered under the license to use. The authors would like also to express their sincere thanks to IDS GeoRadar (Part of Hexagon), for supplying part of the GPR systems, and Ferrovie del Gargano srl for providing facilities and availability of the survey site. Finally, the authors would like to acknowledge Mr. Spartaco Cera for the invaluable support provided in field activities. 


\section{References}

[1]. Frangopol, D. M., Kong, J. S., E Gharaibeh, E. S.. Reliability-Based Life-Cycle Management of Highway Bridges. Journal of Computing in Civil Engineering, 2001; 15(1), 27-34. doi:10.1061/(asce)0887-3801(2001)15:1(27)

[2]. Kerr, A. D., E Moroney, B. E. Track transition problems and remedies. Paper presented at the American Railway Engineering Association, Washington, USA., 1993

[3]. Hölscher, P., E Meijers, P. Literature study of knowledgr and experience of transition zones: Deltares. 2007.

[4]. Li, D., E Davis, D. Transition of Railroad Bridge Approaches. Journal of Geotechnical and Geoenvironmental Engineering, 2005; 131(11): 1392-1398.

[5]. Nicks, J. E. The bump at the end of the railway bridge (Doctor of Philosophy), Texas AEM University; 2009.

[6]. Plotkin, D., E Davis, D. Bridge Approaches and track stiffness (W. Office of Railroad Development, DC 20590, Trans.): Office of Railroad Development, Washington, DC 20590; 2008.

[7]. Kerr, A. D., E Bathurst, L. A. Next Generation high-speed rail program A method for upgrading the performance at track transitions for high-speed service: Office of Railway development, Washington, DC 20590; 2001.

[8]. Li, D., Otter, D., E Carr, G. Railway bridge approaches under heavy axle load traffic: problems, causes, and remedies. Paper presented at the the Institution of Mechanical Engineers, Part F: Journal of Rail and Rapid Transit; 2010.

[9]. Selig, E. T., E Li, D. Track modulus: Its meaning and factors influencing it. In T. R. Record (Ed.), Railroad research issues (pp. 47-54). Washington, USA: Transportation Research Board; 1994.

[10]. Burrow, M. P. N., Bowness, D., E Ghataora, G. S. A comparison of railway track foundation design methods. Paper presented at the the Institution of Mechanical Engineers, Part F: Journal of Rail and Rapid Transit; 2007.

[11]. Bishop, A. W. The principle of effective stress. Teknisk Ukeblad, 1959; 106(39): 895-863.

[12]. Rajeev, P., Chan, D., E Kodikara, J. Ground-atmosphere interaction modelling for long-term prediction of soil moisture and temperature. Canadian Geotechnical Journal. 2012; 49(9), 1059- 1073

[13]. Gräbe, P. J., E Clayton, C. R. I. Effects of Principal Stress rotation on permanent deformation in rail track foundations. Journal of Geotechnical and Geoenvironmental Engineering; 2009; 135(4), 555-565

[14]. Symes, M. J. P. R., Gens, A., E Hight, D. W. Undrained anisotropy and principal stress rotation in saturated sand. Géotechnique. 1984; 34: 11-27.

[15]. Read, D., E Li, D. Research results digest 79 Transit cooperative research program D-7/Task 15 (pp. 38). Pueblo, Colorado: Transportation technology center, Inc. (TTCI). 2006. 
[16]. Sasaoka, C. D., E Davis, D. Implementing track transition solutions for heavy axle load service. Paper presented at the the AREMA 2005 Annual Conference, AREMA. 2005.

[17]. Artagan, S.S., Bianchini Ciampoli, L., D'Amico, F., Calvi, A., Tosti, F., Non-destructive assessment and health monitoring of railway infrastructures, Surveys in Geophysics; 2019; 1-37

[18]. Bianchini Ciampoli, L., Gagliardi, V., Clementini, C., Latini, D., Del Frate, F., Benedetto, A., Transport Infrastructure Monitoring by InSAR and GPR Data Fusion, Surveys in Geophysics, 2019;1-24, https://doi.org/10.1007/s10712-019-09563-7

[19]. Solla M., Lorenzo, H., Riveiro, B., Rial, F.I. Non-destructive methodologies in the assessment of the masonry arch bridge of Traba, Spain. Eng Fail Anal 2011; 18(3):828-835. https://doi.org/10.1016/j.engfailanal.2010.12.009

[20]. Grasmueck M, Viggiano D.A. Integration of ground-penetrating radar and laser position sensors for real-time 3-D data fusion. IEEE Trans Geosci Remote Sens 2007; 45(1):130-137. https ://doi.org/10.1109/TGRS.2006.88225 3

[21]. Berkovic G, Shafir E, Optical methods for distance and displacement measurements. Adv Opt. Photonics, 4, 441, 2012

[22]. Tsunashima H, Naganuma Y, Matsumoto A et al., Condition monitoring of railway track using inservice vehicle. Reliability and Safety in Railway.2012. doi:10.5772/35205

[23]. Malar R, Jayalakshmy S, Detection of cracks and missing fasteners in railway lines using structure topic model. IJISET - Int J Innov Sci Eng Technol. 2015; 2(10): 369-375

[24]. Santa-aho S, Nurmikolu A, Vippola M., Automated ultrasound-based inspection of rails: review. Int J. Railw 2017; 10: 2129 ,

[25]. De Bold RP, Non-destructive evaluation of railway trackbed ballast. PhD Thesis, The University of Edinburgh, 2011.

[26]. Woodward, P.K., Kennedy, J., Laghrouche, O., Connolly, D.P., Medero, G., Study of railway track stiffness modification by polyurethane reinforcement of the ballast. Transp Geotech 2014;1:214-224.

[27]. Chang L, Dollevoet RPBJ, Hanssen RF, Nationwide railway monitoring using satellite SAR interferometry. IEEE J Sel Top Appl Earth Obs Remote Sens 2017; 10:596-604.

[28]. Zheng, X. Yang, Z., Ma, H., Ren, G., Zhang, K. Yang, F., Li. G, Integrated Ground-Based SAR Interferometry, Terrestrial Laser Scanner, and Corner Reflector Deformation Experiments, Sensors, 2018; 18(8): 4401.

[29]. Annan A.P. Ground Penetrating Radar Workshop Notes Sensors and Softwares Inc., Ontario, Canada, 2001.

[30]. Daniels, D.J. Ground Penetrating Radar, 2nd ed.; The Institution of Electrical Engineers: London, UK, 2004.

[31]. Lahouar, S.; Al-Qadi, I.L. Automatic detection of multiple pavement layers from GPR data. Non-Destr. Test. Eval. Int., $2008 ; 41,69-81$. 
[32]. Loizos, A.; Plati, C. Accuracy of pavement thicknesses estimation using different ground penetrating radar analysis approaches. Non-Destr. Test. Eval. Int., 2014; 62, 55-65.

[33]. Bianchini Ciampoli, L., Tosti, F., Economou, N., Benedetto, F., Signal processing of GPR Data for Road Surveys, Geosciences, 2019; 9(96)

[34]. Roberts R, Al-Qadi I, Tutumluer E, Boyle J, Sussmann TR. Advances in railroad ballast evaluation using 2 GHz horn antennas. In: Proceedings of the $11^{\text {th }}$ international conference on ground penetrating radar; 2006. Columbus, OH., USA.

[35]. Fontul, S.; Fortunato, E.; De Chiara, F.; Burrinha, R.; Baldeiras, M. Railways Track Characterization Using Ground Penetrating Radar. Procedia Eng. 2016; 143: 1193-1200.

[36]. Bianchini Ciampoli, L., Artagan, S., Tosti, F., Gagliardi, V., Alani, A. M., Benedetto, A., A comparative investigation of the effects of concrete sleepers on the GPR signal for the assessment of railway ballast. 17th International Conference on Ground Penetrating Radar (GPR).2018. doi:10.1109/icgpr.2018.8441588

[37]. Benedetto, A., Bianchini Ciampoli, L., Brancadoro, M.G., Alani, A.M., Tosti, F. A Computer-Aided Model for the Simulation of Railway Ballast by Random Sequential Adsorption Process. Computer-Aided Civil and Infrastructure Engineering, 33 (3), pp. $243-$ 257, 2018.

[38]. Bianchini Ciampoli, L., Calvi, A., D'Amico, F., Railway Ballast Monitoring by GPR: A Test-Site Investigation, Remote Sensing, 2019; 11(20): 2381,

[39]. Tosti, F., Benedetto, A., Calvi, A., Bianchini Ciampoli, L. Laboratory investigations for the electromagnetic characterization of railway ballast through GPR (2016) Proceedings of 2016 16th International Conference of Ground Penetrating Radar, GPR 2016, art. no. 7572605 .

[40]. Tosti, F. and Ferrante, C., Using Ground Penetrating Radar methods to investigate reinforced concrete structures, Surveys in Geophysics, 2019; 1-46,

[41]. Kashif Ur Rehman S et al, Nondestructive test methods for concrete bridges: a review. Construction and Building Materials, $107: 58-86,2016$.

[42]. Alani, A.M. Aboutalebi, M., Kilic, G., Applications of ground penetrating radar (GPR) in bridge deck monitoring and assessment, J. Appl. Geophys., 2013; 97:45-54.

[43]. Benedetto, A., A three dimensional approach for tracking cracks in bridges using GPR, J. Appl. Geophys., vol. 97, pp. 3744, 2013.

[44]. Benedetto, A., Manacorda, G., Simi, A., Tosti, F. Novel perspectives in bridges inspection using GPR. Nondestructive Testing and Evaluation. 2012; 27 (3): 239-251. 
[45]. Ferretti A, Prati C, Rocca F., Nonlinear subsidence rate estimation using permanent scatterers in differential SAR interferometry. IEEE Trans Geosci Remote Sens , 2000; 38(5):2202-2212.

[46]. Berardino P., Fornaro G., Lanari R., E. Sansosti. A new algorithm for surface deformation monitoring based on small baseline differential SAR interferograms. IEEE Transactions on Geoscience and Remote Sensing, 40 (11) (2002), pp. 2375-2383

[47]. Crosetto M., Crippa B., Biescas E. Early detection and in-depth analysis of deformation phenomena by radar interferometry Engineering Geology, 2005: 79 (1-2) pp. 81-91

[48]. Hooper A., Zebker H., Segall P., Kampes B. A new method for measuring deformation on volcanoes and other natural terrains using InSAR persistent scatterers Geophysical Research Letters, 2004; 31 p. L23611., 10.1029/2004GL021737

[49]. Luo R.C., Yih C-C, Su K.L. Multisensor fusion and integration: approaches, applications, and future research directions. IEEE Sens J 2002;:2(2):107-119,

[50]. Pepe, A.; Calò, F. A Review of Interferometric Synthetic Aperture RADAR (InSAR) Multi-Track Approaches for the Retrieval of Earth's Surface Displacements. Appl. Sci. 2017, 7, 1264.

[51]. Moreira A., Prats-Iraola P., Younis M., Krieger G., Hajnsek I. and Papathanassiou K. P., "A tutorial on synthetic aperture radar," in IEEE Geoscience and Remote Sensing Magazine, 2013; 1( 1): 6-43.

[52]. Ferretti A, Prati C, Rocca F. Permanent Scatterers in SAR interferometry. IEEE Trans Geosci Remote Sens 39(1):8-20, 2001

[53]. Koudogbo F., Urdiroz A., Robles J.G., Chapron G., Lebon G., Fluteaux V., Priol G. Radar interferometry as an innovative solution for monitoring the construction of the Grand Paris Express metro network-first results. In: World tunnel conference, 2-25 April, Dubai, 2018

[54]. Barla, G., Tamburini, A., Del Conte, S., Giannico, C., InSAR monitoring of tunnel induced ground movements. Geomechanik und Tunnelbau 9(1):15-22, 2016.

[55]. Yang Z., Schmid F., Roberts C. Assessment of railway performance by monitoring land subsidence.In: 6th IET conference on railway condition monitoring (RCM 2014), pp 1-6, 2014

[56]. Tosti F., Gagliardi V., D'Amico F., Morteza (Amir) A., (2019). Transport infrastructure monitoring by data fusion of GPR and SAR imagery information. In: Conference: AIIT 2nd International Congress on Transport Infrastructure and Systems in a Changing World, TIS2019 At: Rome, Italy

[57]. Bianchini Ciampoli, L., Gagliardi, V., Calvi, A., D'Amico, F., Tosti, F. Automatic network-level bridge monitoring by integration of InSAR and GIS catalogues. Proceedings of SPIE - The International Society for Optical Engineering, 2019; 11059. doi: $10.1117 / 12.2527299$ 
[58]. Colla, C., Krause, M., Maierhofer, C., Höhberger, H.-J., Sommer, H., Combination of NDT techniques for site investigation of non-ballasted railway tracks. NDT and E Int 2002; 35(2):95-105.

[59]. Heggy, E., Wada, K., Khan, S. D., Staudacher, T., Kaminski, E. Gabsi, T. Mapping buried and exposed lava flows in arid volcanic terrains using polarimetric and multiple frequencies SAR and GPR, IEEE International Geoscience E Remote Sensing Symposium, 2008.

[60]. Gutiérrez F, Galve JP, Lucha P, Castañeda C, Bonachea J, Guerrero J. Integrating geomorphological mapping, trenching, InSAR and GPR for the identification and characterization of sinkholes: A review and application in the mantled evaporite karst of the Ebro Valley (NE Spain). Geomorphology, 2011: 134:144 -56,

[61]. Martel R, Castellazzi P, Gloaguen E, Trépanier L, Garfias J. ERT, GPR, InSAR, and tracer tests to characterize karst aquifer systems under urban areas: The case of Quebec City. Geomorphology;310:45 -56, 2018

[62]. Bianchini Ciampoli, L., Artagan S.S., Tosti F., Calvi A., Alani A.M., Benedetto, A., A GPR spectral-based filtering for minimization of concrete sleepers effects in railway ballast investigations, , 41st International Conference on Telecommunications and Signal Processing July, Athens, Greece, 2018. doi: 10.1109/tsp.2018.8441461

[63]. Benedetto, F., Tosti, F. A signal processing methodology for assessing the performance of ASTM standard test methods for GPR systems, Signal Processing, 2017; 132: 327-33.

[64]. Sarmap. SARscape technical description. http://www.sarmap.ch/pdf/SARscapeTechnical.pdfl; 2012 [accessed 11 February 2020]

[65]. Sarmap. SAR-Guidebook. http://www.sarmap.ch/pdf/SAR-Guidebook.pdf; 2009 [ accessed 11 February 2020] [66]. Jiang, Y., Liao, M., Wang, H., Zhang, L., Balz, T., Deformation Monitoring and Analysis of the Geological Environment of Pudong International Airport with Persistent Scatterer SAR Interferometry, Remote Sensing, 2016; 8(12): 1021. 